\title{
SPATIAL AND TEMPORAL IMAGING OF A COVER-COLLAPSE SINKHOLE IN WEST-CENTRAL FLORIDA THROUGH HIGH RESOLUTION REMOTE SENSING AND GEOPHYSICAL TECHNIQUES
}

\section{Christine Downs}

Digital Heritage \& Humanities Center, University of South Florida, 4202 E Fowler Ave., Tampa, FL 33620, cmdowns@usf.edu

\section{Tonian Robinson}

School of Geoscience, University of South Florida, 4202 E Fowler Ave., Tampa, FL 33620,trobinson@usf.edu

\section{Garrett Speed}

Digital Heritage \& Humanities Center, University of South Florida, 4202 E Fowler Ave., Tampa, FL 33620, gspeed@usf.edu

\section{Jorge Gonzalez Garcia}

Digital Heritage \& Humanities Center, University of South Florida, 4202 E Fowler Ave., Tampa, FL 33620,

jorgegonzale@usf.edu

\section{Noelia Garcia}

Digital Heritage \& Humanities Center, University of South Florida, 4202 E Fowler Ave., Tampa, FL 33620,

mariagarciaa@usf.edu

\section{Lori Collins}

Digital Heritage \& Humanities Center, University of South Florida, 4202 E Fowler Ave., Tampa, FL 33620, lcollins@usf.edu

\section{Travis Doering}

Digital Heritage \& Humanities Center, University of South Florida, 4202 E Fowler Ave., Tampa, FL 33620 ,

tdoering@usf.edu

\section{Shawn Landry}

Water Institute, University of South Florida, 4202 E Fowler Ave., Tampa, FL 33620, landry@usf.edu

\section{David Eilers}

Water Institute, University of South Florida, 4202 E Fowler Ave., Tampa, FL 33620, eilers@usf.edu

\section{Sajad Jazayeri}

School of Geoscience, University of South Florida, 4202 E Fowler Ave., Tampa, FL 33620, sjazayeri@mail.usf.edu

\section{Sanaz Esmaeili}

School of Geoscience, University of South Florida, 4202 E Fowler Ave., Tampa, FL 33620, esmaeili@mail.usf.edu

\section{Sarah Kruse}

School of Geoscience, University of South Florida, 4202 E Fowler Ave., Tampa, FL 33620, skruse@usf.edu

\section{Jochen Braunmiller}

School of Geoscience, University of South Florida, 4202 E Fowler Ave., Tampa, FL 33620 jbraunmiller@usf.edu

\section{Henok Kiflu}

G3 Group, 2509 Success Dr \#1, Odessa, FL, 33556, henok.kiflu@g3group.com 


\section{Abstract}

On July 14, 2017, a cover-collapse sinkhole formed in the front yard of a home in Pasco County, FL. Starting as a depression, the initial collapse occurred rapidly (120 minutes) with subsequent slumping over the course of three days. The sinkhole is oval and coneshaped with a northeast-southwest long axis and ridges on the northwest and west slopes. A combination of remote sensing, geophysics, and soil borings are used to characterize the temporospatial surface changes and subsurface structures at this sinkhole. Repeat surveys started four days post-collapse and concluded 10 months post-collapse. Surface changes over time are computed using terrestrial laser scanning (TLS) and drone-based structure-from-motion (SfM) photogrammetry, with the Multiscale Model to Model Cloud Comparison algorithm. The initial collapse area measured 1,395 square meters (day 4) and grew to a maximum of 1,626 square meters (day 32) before stabilization efforts partially the sinkhole and built up the perimeter walls. Post-collapse and pre-stabilization activity in the form of perimeter growth occurred on the northeast and southwest edges. Ground-penetrating radar detected a semicontinuous horizon within sands and silts that appears to correspond to the historic ground surface present before portions of the nearby Saxon Lake were filled in as part of agricultural and housing development modifications to the area in the 1960s and 1970s. The direction of the collapse's long axis, post-collapse activity, and the orientation and depth of a semicontinuous subsurface horizon all suggest a northeast-southwest trending linear or elongated karst feature contributed to the collapse and subsidence.

\section{Introduction}

On July 14, 2017, a cover-collapse sinkhole occurred in the front yard of a home in Pasco County (Figure 1). Starting as a depression, the initial collapse occurred rapidly with subsequent slumping happening for three days. Two homes were destroyed; seven surrounding properties were deemed unsafe. By July 19, the water and debris-filled collapse measured approximately 52 meters southwest-northeast and 42 meters northwest-southeast.

The collapse is located in west-central Florida within the Ocala Uplift physiographic district, which is defined by karstic bedrock close to the ground surface and a layer of undifferentiated sand and clay of variable thickness covering it (Tihansky 1999). A cover-collapse occurs where the increased cohesion of a relatively higher clay content

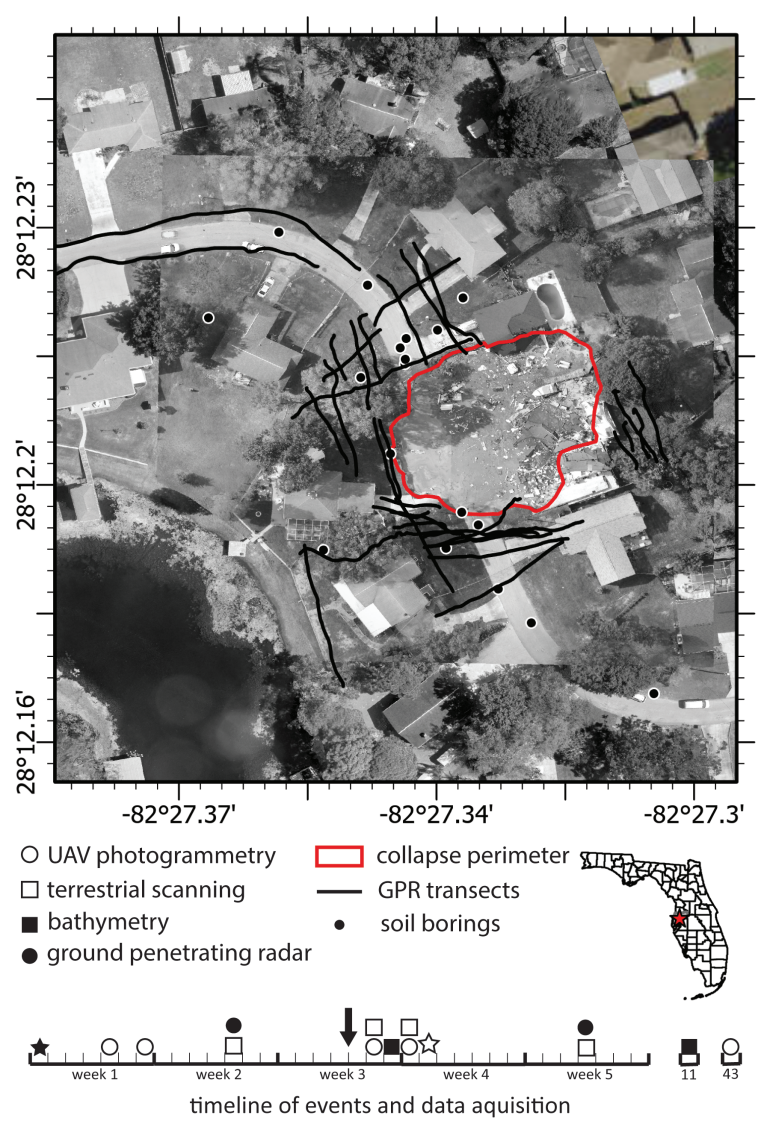

Figure 1. Data coverage map for each technique. TLS and UAV photogrammetry coverage is shown as coverage extent as opposed to point locations of the scanner, targets, and drone position for presentation purposes. Timeline of events and data collection starting with the initial collapse (red polygon) and including the start of stabilization (arrow). The frequency of repeat acquisition was different for each method. Ground-penetrating radar was collected on different days, but ground coverage does not overlap.

in the overburden delays failure until a collapse happens (Sinclair et al. 1985).

Locally, the subsurface consists of 3 to 4.5 meters of silty sand underlain by clayey sand to sandy clays that overlie a weathered limestone (Geotechnical Environmental Consultants 2017; Professional Service Industries 2018). Seismic data suggests this total cover thickness may be locally as large as $20 \mathrm{~m}$. The groundwater levels are seasonal and highly dependent on rainfall. Following the collapse, the water table ranged from 0.9 to 1.8 meters below the surface (Professional Service Industries 2018). 
The immediate objectives of this project were to capture the initial morphology of the sinkhole and take repeat measurements at daily, weekly, and monthly intervals to document changes. Terrestrial laser scanning (TLS) (Jones 2006; Perroy et al. 2010; Viles 2016; Tilly and Kelterbaum 2017; Benito-Calvo et al. 2018), and dronebased structure-from-motion (SfM) photogrammetry (Colomina and Molina 2014; James et al. 2017; Petschko et al. 2017) have been shown to rapidly and accurately record terrain and surface features. Geophysical methods are also useful for characterizing the subsurface (Gutiérrez et al. 2011; Gómez-Ortiz and Martín-Crespo 2012; Viles 2016). A combined survey strategy using integrated 3D data acquisition can yield valuable understanding of rapidly-occurring, multiscale events (Collins et al. 2017).

In this paper, we present the results of repeat TLS and unmanned aerial vehicle (UAV)-based SfM photogrammetry survey, and bathymetric measurements used to capture the surface features in and around the sinkhole, and ground-penetrating radar (GPR) data used to characterize the subsurface in the immediate vicinity surrounding the sinkhole. Repeat surface measurements provide a temporal component to the high-resolution spatial data necessary to detect small changes in three-dimensional space.

\section{Methods}

Each dataset has its own horizontal and vertical spatial resolution (Table 1). We note that two seismometers were installed around the sinkhole to detect sinkhole growth, but anthropogenic noise obscured almost any possible signals from the natural system. One natural event-a wall collapse on the west side of the sinkhole-was recorded 22 days post-collapse and overnight when heavy equipment, cars, and home air conditioning systems are off or minimally running.

\section{Surface}

TLS of the collapse and surrounding area was conducted four times (July 25, August 2, August 4, August 14, 2017) post-collapse. Using two FARO Focus 330 phaseshift 3D laser scanners ( $2 \mathrm{~mm}$ resolution), each survey completed approximately 30 scans from positions along a transect that circumvented the collapse. Scans were placed at intervals that ensured line of sight coverage. External spherical targets were placed at various elevations around the sinkhole and used for registration control from one scan position to the next. Scans were

\begin{tabular}{|l|c|c|}
\hline & horizontal & vertical \\
\hline TLS & $2 \mathrm{~mm}$ & $2 \mathrm{~mm}$ \\
\hline SfM & $<20 \mathrm{~cm}$ & $<20 \mathrm{~cm}$ \\
\hline GPR & $1 \mathrm{~cm}$ & $5-17 \mathrm{~cm}$ \\
\hline Water depth (hand probe) & $1.5 \mathrm{~m}$ & $\sim 50 \mathrm{~cm}$ \\
\hline Water depth (sonar) & $0.10-3 \mathrm{~m}$ & $3 \mathrm{~cm}$ \\
\hline
\end{tabular}

Table 1. Data resolution by field method.

processed in SCENE (FARO) and aligned using targetbased registration. Registration error ranged from 2.9$5.9 \mathrm{~mm}$ with the largest error occurring between scans of tree canopy.

Aerial UAV surveys were flown five times in the seven weeks after the collapse (plus a final flight 43 weeks post-collapse) with an unmodified DJI Mavic Pro quadcopter UAV. Photos taken during a flight measure the position of at least six ground control points. Photos were captured during free flight up to 122 meters above the ground, with all areas of the ground having at least nine photos covering that location. Ground control points were captured using a Trimble Geo7x with the centimeter package and a Zephyr 3 antenna. Photogrammetry was carried out using Photoscan Professional 1.4 (AgiSoft) and exported as point clouds. Resolution, as reported in orthoimages, ranges from 0.92 to $2.47 \mathrm{~cm}$.

Additionally, commercial aerial UAV company Halo Imaging flew five additional times in July 2017 in the two weeks following the collapse. Halo Imaging deployed a Sensefly Real-time kinematic (RTK) Ebee fixed-wing UAV and processed their imagery in Pix4D Mapper software to produce point clouds, digital surface models, and orthophotos. Halo Imaging provided raw images from their surveys, as well as their processed photogrammetry derivatives.

To detect changes in the collapse's perimeter and volume as remediation progressed, repeat surveys were compared relative to each other. Since no control (precollapse) data exists, all data is compared relative to the first-day measurements (July 18, 2019, four days after the collapse). TLS and SfM photogrammetry are handled as point clouds- each dataset existing as its own point cloud. Point clouds are brought into CloudCompare v.2 and aligned in 3D by surrounding infrastructure not damaged by the collapse (i.e., house roof corners). Moving and temporary features (i.e., people, equipment, cars) are removed with the qBroom plugin. 
By looking at changes in the perimeter alone we can see changes in the sinkhole's surface extent. However, the perimeter is determined by a plane-view line of sight. Small changes along the walls of the sinkhole, within the water or under overhanging features (i.e., tree canopy) area not accounted for. By comparing point clouds with the $\mathrm{M} 3 \mathrm{C} 2$ algorithm, changes in all directions can be detected and quantified.

Point clouds were compared to each other using the Multiscale Model to Model Cloud Comparison algorithm (M3C2) (Lague et al. 2013). For each point in a subset of points from the first point cloud (the data that was collected first), a surface normal was calculated based on neighboring points within a defined radius. The surface to this normal was compared to the surfaces in a second cloud (the data that was collected at a later time). This approach is more effective than simply calculating the difference in $\mathrm{z}$-value between point cloud because it can determine changes occurring underneath tree canopy and overhangs. Furthermore, M3C2 measures the precision of a given set of points-based surface roughness to determine if a measured change is considered significant (aka real) or a product of inherently irregular surfaces.

\section{Subsurface}

GPR transects were collected two weeks post-collapse and again at five weeks. GPR data were collected as a grid south of the collapse and a series of profiles running tangential to and radially out from the collapsed perimeter (Figure 1) using the MALÅ ProEx system and a $250 \mathrm{MHz}$ shielded antennae. GPS positioning was synchronously collected using a Trimble R10 rover and Zephyr 3 antenna. A best fit average velocity for the whole data set $(0.08 \mathrm{~m} / \mathrm{ns})$ was determined by fitting diffraction patterns in the data to a velocity model. Data was processed in ReflexW (Sandmeier, Inc.). Profile data points (traces) were interpolated to be equidistance in the transect direction. A dewow filter was then applied to remove the long wavelength component. A time-zero correction was performed to shift the first positive peak to the direct wave arrival time. A step-wise average of 100 traces were subtracted along the profile followed by a three-trace running average subtraction. A gain was applied and return signals later than 160 ns were cut off as little to no useful information was returned. Travel time was converted to depth with a constant ground velocity.

Existing soil borings were used to correlate horizons imaged with GPR to lithology and strata. Additionally, the horizons are interpolated between GPR transects to produce a surface map to compare with the extent and depth of lithologic layers identified from soil borings.

\section{Bathymetry}

Water depth within the sinkhole was mapped on two different days (August 3 and October 5). The first survey was conducted by boat with a soil probe and measuring tape performed in an evenly-spaced grid fashion $(n=120)$. The available contour map (Geotechnical Environmental Consultants 2017) was digitized to compare with the subsequent survey.

After the debris was removed from the water, the bottom of the collapse was mapped using a Lowrance HDS 5 Gen 2 Wide Area Augmentation System (WAAS) enabled Global Positioning System (GPS) with fathometer (bottom sounder) to determine the boat's position and bottom depth in a single measurement. Measurements were collected every $10 \mathrm{~cm}$ in circular transects with approximately 3-meter transect spacing. The data was then exported into ArcGIS Pro (ESRI) for processing using triangular irregular network (TIN) modeling to create a basis for bathymetric contour creation. The result is an estimate of the collapse's area, mean and maximum depths, and volume.

Water depth data points were converted to point clouds for the $\mathrm{M} 3 \mathrm{C} 2$ algorithm and integration with terrain point clouds.

\section{Results \\ Surface Changes}

Here we highlight the ability to capture changes over time by focusing on data acquired before and after known post-collapse events (Figure 2). These events include the removal of two houses and associated structures that intersected the sinkhole on the east and north side. These structures gradually collapsed over the course of three weeks until they were completely removed by mid-August. Stabilization efforts began in August 2017, which added large volumes of fill material in and around the sinkhole, and was used to build a rim around the perimeter of the collapsed area. During stabilization, seismic activity not associated with anthropogenic noise is interpreted to be a machinery-induced wall collapse in early August. Seismic records from October 2017 to April 2018 suggest no significant sinkhole activity. A final UAV-flight was done in May 2018, which is compared to 

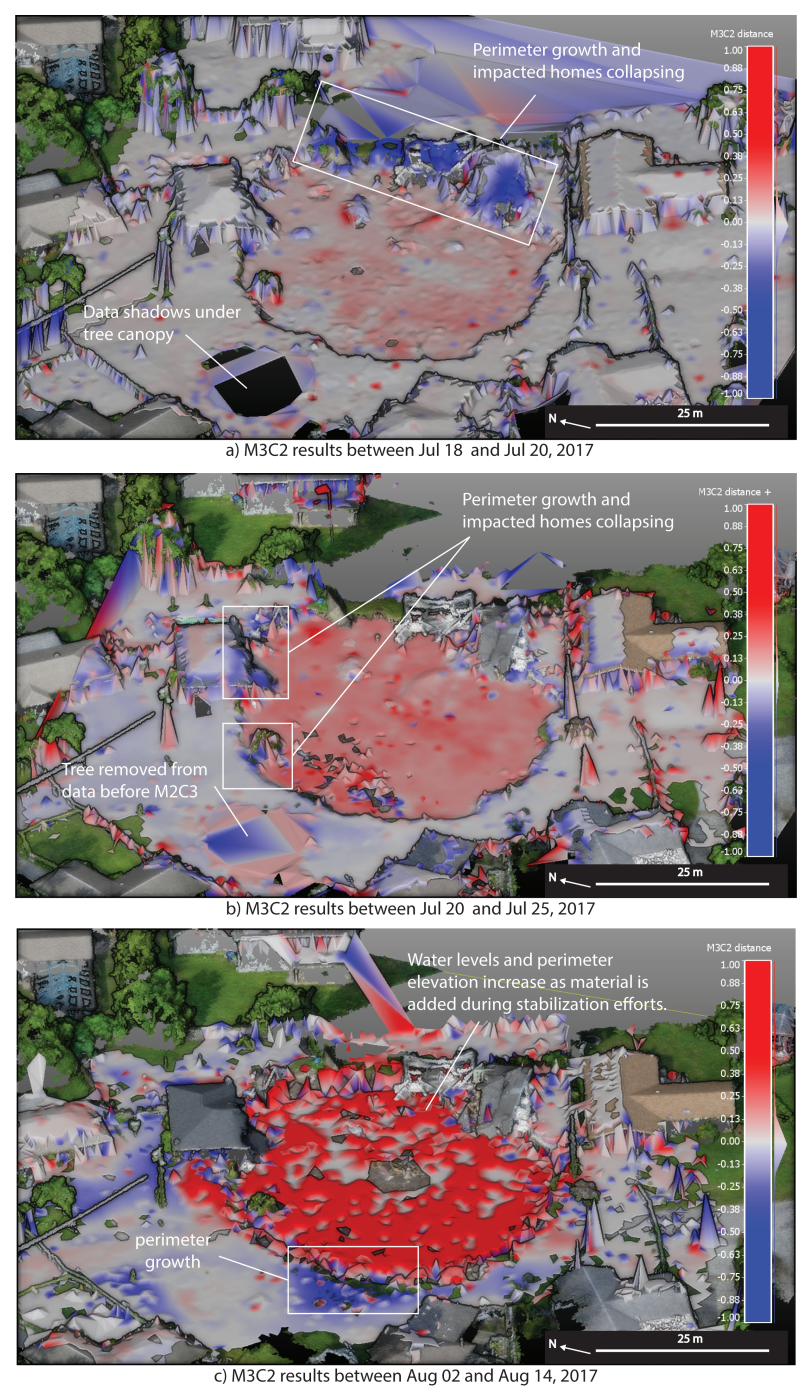

Figure 2. Results of an M3C2 algorithm between SFM photogrammetry datasets on July 18 and July 20, 2017; SfM photogrammetry and terrestrial scanning on July 20 and July 25, 2017; and terrestrial scanning datasets on August 02 and 14 , 2017. All results are underlain with July 18, 2017 photogrammetry-derived point cloud for reference. The largest negative change occurs where the perimeter grew (along the east edge July 18-20 and the southwest edge Aug 2-14) and where a partially destroyed home collapsed completely. There is little change detected between July 25 and August 2 (not shown). Small areas of a relatively large change within the sinkhole is due to debris movement. The sinkhole as a whole does experience a positive change in the beginning of August due to large volumes of fill added and increasing water levels. Changes in tree canopy have been removed. the first post-collapse dataset. The two homes partially collapsed when the sinkhole formed and the one on the east edge continued to collapse inward as the perimeter grew. Results from the $\mathrm{M} 3 \mathrm{C} 2$ algorithm shows a negative surface change between July 18 and July 20 where that house stood (Figure 2a). Although the house on the north edge had also partially collapsed, no change occurred during this time. The water surface within the sinkhole does show a larger positive change, which is attributed to water levels rising.

$\mathrm{M} 3 \mathrm{C} 2$ results show a small positive change within the sinkhole between July 20 and July 25 as water levels continued to rise (Figure 2b). Negative surface changes are detected along the side of the partially standing house indicating further damage. Additionally, a negative change is detected on the northwest edge of the sinkhole where more ground material collapsed.

Stabilization efforts began at the beginning of August. $\mathrm{M} 3 \mathrm{C} 2$ results from Aug 02 to Aug 14 show more negative change at the site of the houses, which by this time had been removed completely (Figure 2c). The entire sinkhole and much of the edge show a positive change. Water levels in the sinkhole had stabilized by this time so this positive surface change is likely water levels being displaced by large volumes of fill material. It is also fill material that accounts for the positive change around the perimeter.

Seismic records detected sinkhole-related activity on $\mathrm{Au}-$ gust 5 , interpreted to be a wall collapse. This activity is represented in the $\mathrm{M} 3 \mathrm{C} 2$ results as a negative change along the western edge of the sinkhole. There is also negative surface change to the northwest of the sinkhole that may be the results of heavy machinery compacting the top soil.

Over the course of the study, the most prominent changes are negative surface changes where the two houses once stood and a positive change along the perimeter where a stabilizing rim was constructed. $\mathrm{M} 3 \mathrm{C} 2$ results from July 18, 2017 to May 05, 2018 do not show surface changes due to perimeter growth as they are overprinted by changes made during stabilization efforts (Figure 3). Nevertheless, negative change is detected on the western edge where the wall collapse occurred. The negative change within the sinkhole is likely due to a large amount of debris in the first dataset that was later removed and not present in the second comparative dataset. 


\section{Subsurface Changes}

The M3C2 algorithm was not able to determine any significant change between bathymetry data on August 03, 2017 and October 5, 2017 because the change in water depth between surveys was so large and minimal threedimensional overlap exists. A total of 10,432 cubic meters of material was used to partially fill the sinkhole and stabilize the walls. Not surprisingly, this results in a drastic decrease in water depths and substantial change to the overall shape of the collapse.

The total volume from the first bathymetric survey (Aug 03 ) is 7,600 cubic meters (Figure 4a). The surface water's stage was $1.6 \mathrm{~m}$ below the ground surface and exhibited a maximum depth of $12.2 \mathrm{~m}$. The sinkhole is generally oval-shaped with a northeast-southwest trending long axis. Within the sinkhole there are ridges on the northwest and west walls. The total volume from the second survey (October 5) is 1,945 cubic meters, representing a $75 \%$ decrease (b). The bottom of the sinkhole, besides becoming much shallower with a maximum depth of 3 meters, now has a flat bottom. There were 21 measurements collected within the region that exhibited the deepest depths (up to $5 \mathrm{~m}$ ). (Figure 4b, red circle). These data points are not typical of a slope found in natural systems and may represent a small vertical opening or depth anomaly caused by bottom debris. The water levels did not change, but the ground has been built up around the sinkhole putting it 3 meters below the ground surface.

\section{Subsurface Structures}

Standard penetration tests (SPT) and cone penetrometer tests (CPT) are in-situ tests performed to quantify soil strength and were available in consultant reports (Geotechnical Environmental Consultants 2017; Professional Service Industries 2018). About 3-4.5 meters of loose sand is underlain by sediment with varying ratios of sand and silt down to 11-13 meters below the ground surface. About 2.5-3 meters of soft clay or silty clay lies beneath sand and silt before borings encountered firm limestone.

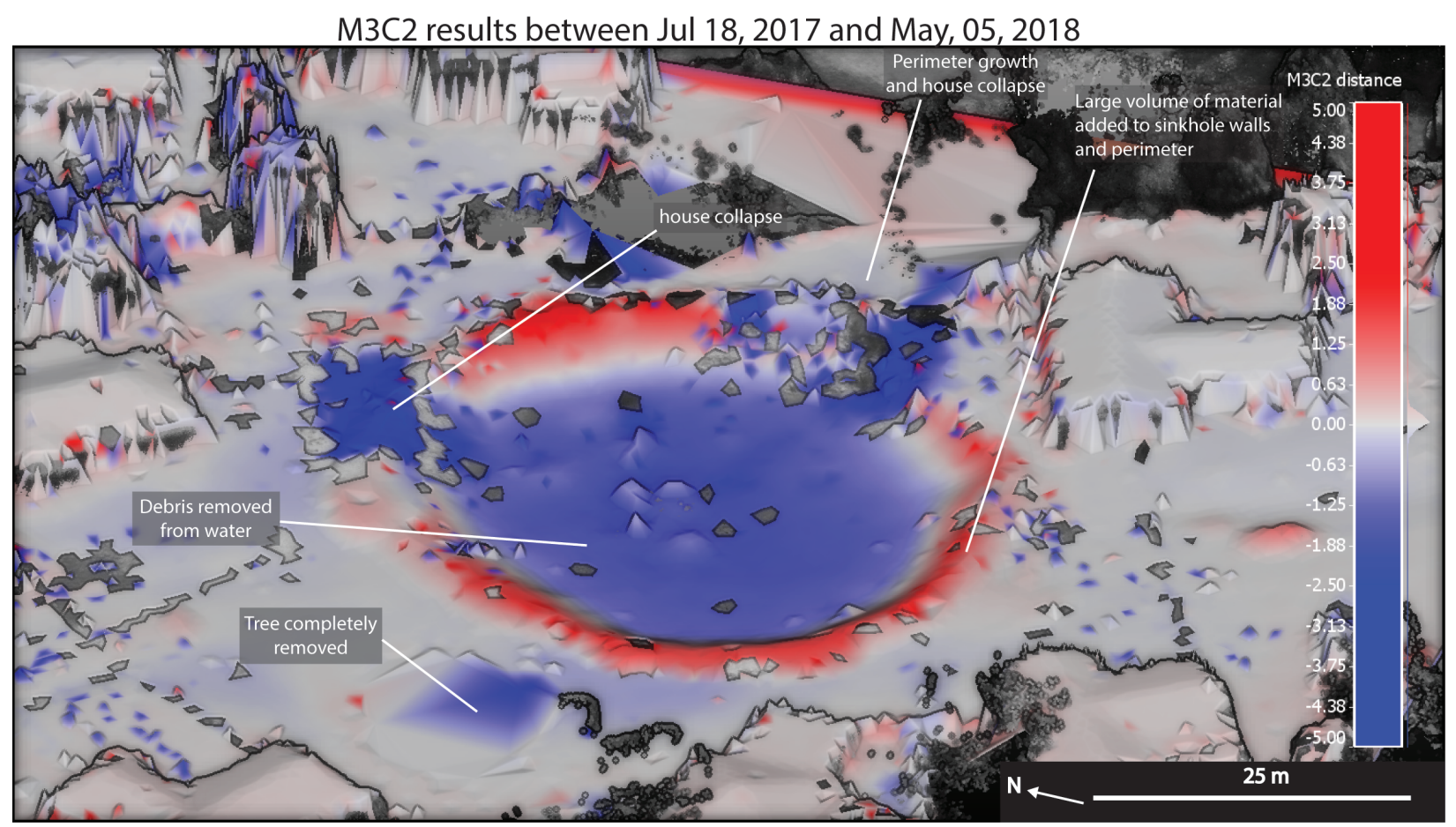

Figure 3. Relatively large changes as determined by the M3C2 algorithm between SfM photogrammetry datasets on July 18, 2017 and May 05, 2018 underlain with May 05, 2018 photogrammetry-derived point cloud for reference. The most notable negative changes (blue) correspond to houses that collapsed and were removed, perimeter growth on the east side of the sinkhole, and the complete removal of a tree to the west of the sinkhole. The most notable positive change (red) corresponds to the built-up rim around the sinkhole. Additionally, perimeter growth occurred on the southwest edge, but it is overprinted by the rim. The water levels within the sinkhole were slightly lower in May 2018 than immediately following the collapse in July 2017. Changes in tree canopy have be removed. 


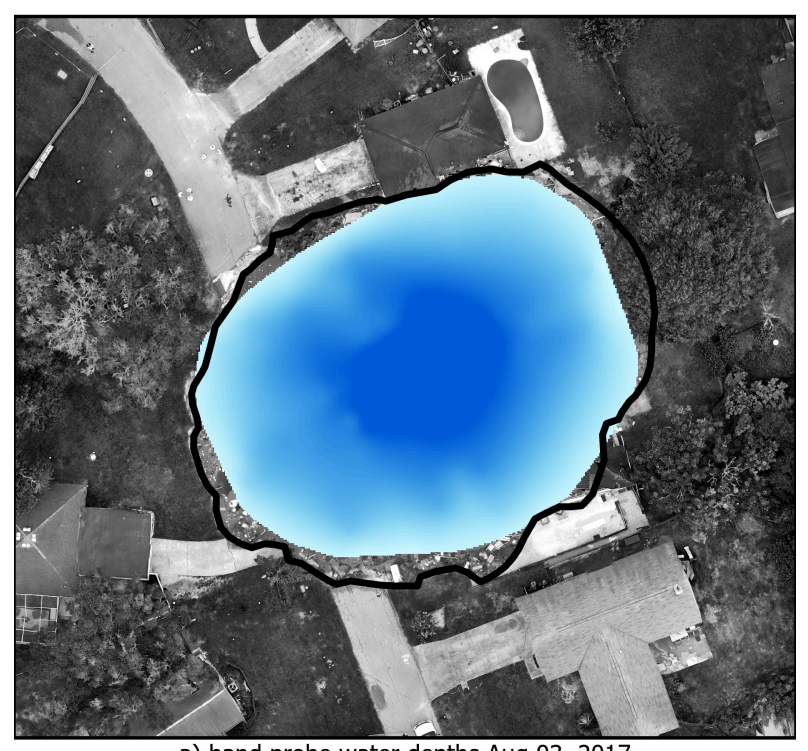

a) hand probe water depths Aug 03, 2017

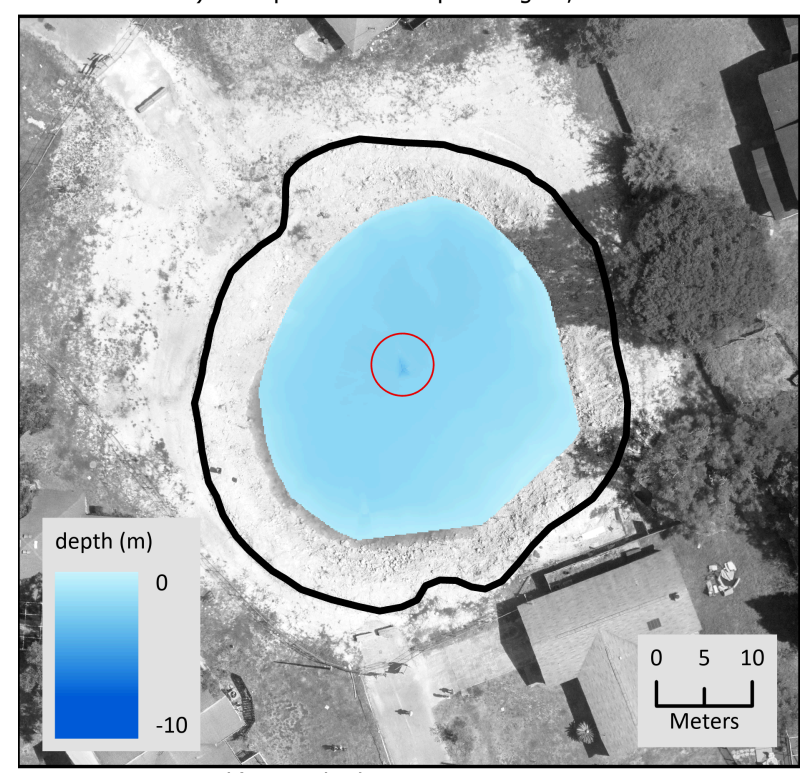

b) sonar bathymetry Oct 05, 2017

Figure 4. Side by side comparison of sinkhole bathymetry. Water levels remained relatively constant after the initially syn-collapse rise. (A) Before stabilization efforts began the sinkhole was generally oval and cone-shaped with a northeast-southwest trending long axis and ridges on the northwest and west walls. Maximum water depth is 12.2 meters. (B) Post-stabilization measurements show a significant decrease in water depths (3 meters maximum) and flattened bottom. The red circle denotes data points not typical of a slope found in a natural system and may represent a small vertical opening or depth anomalies caused by bottom debris.
GPR coverage surrounding the sinkhole was limited by accessibility. Nevertheless, a high-amplitude semi continuous horizon is observed in numerous GPR profiles (Figure 5). It resides within a sand to silt layer and corresponds to changes in physical properties, but not necessarily a lithological contact. The interpolated surface for this horizon is compared to the depth of the top of limestone and the historic lake boundary (Figure 6). The horizon is shallowest $(<0.5 \mathrm{~m})$ to the northeast and generally dips to the southwest. On the western edge of the sinkhole, the horizon is $1.25-1.75$ meters deep and deepens steeply $(2.5+\mathrm{m})$ to the southwest. Interruptions in or down warping of the horizon were noted in consulting reports (Professional Service Industries 2018) as GPR anomalies associated with downward migration of sediments. The horizon resides within a sand to silt layer and corresponds to changes in physical properties, but not necessarily a sharp lithological contact (i.e., sand over clay). The areas in which the horizon is the deepest were once a part of the Saxon Lake as seen in historic aerial imagery with the shoreline indicated by the gray line depicted in Figure 6. The top of limestone is highly variable but is generally deepest around the sinkhole. The horizon is deepest where the top of clay is also deepest (18 $\mathrm{m}$ deep) and the lithology alternates between weathered limestone, clays, and sands.

\section{Discussion}

The most prominent post-collapse surface changes are the continued collapse and subsequent removal of two houses, rising water levels within the sinkhole, and perimeter growth. Perimeter growth, due to overburden failure, occurs along the northeast and southwest edge, which is also the direction of the long axis.

When the first surface dataset (July 18, 2017, four days post-collapse) is compared with the last dataset (May 05,

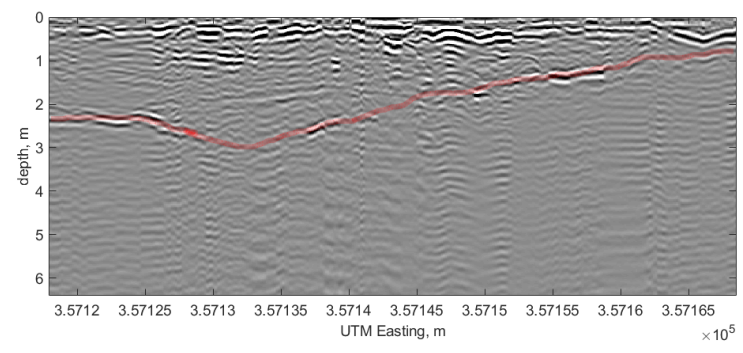

Figure 5. Example of the high-amplitude, semicontinuous horizon observed in GPR and used to interpolate a surface within the uppermost unconsolidated sediment. 


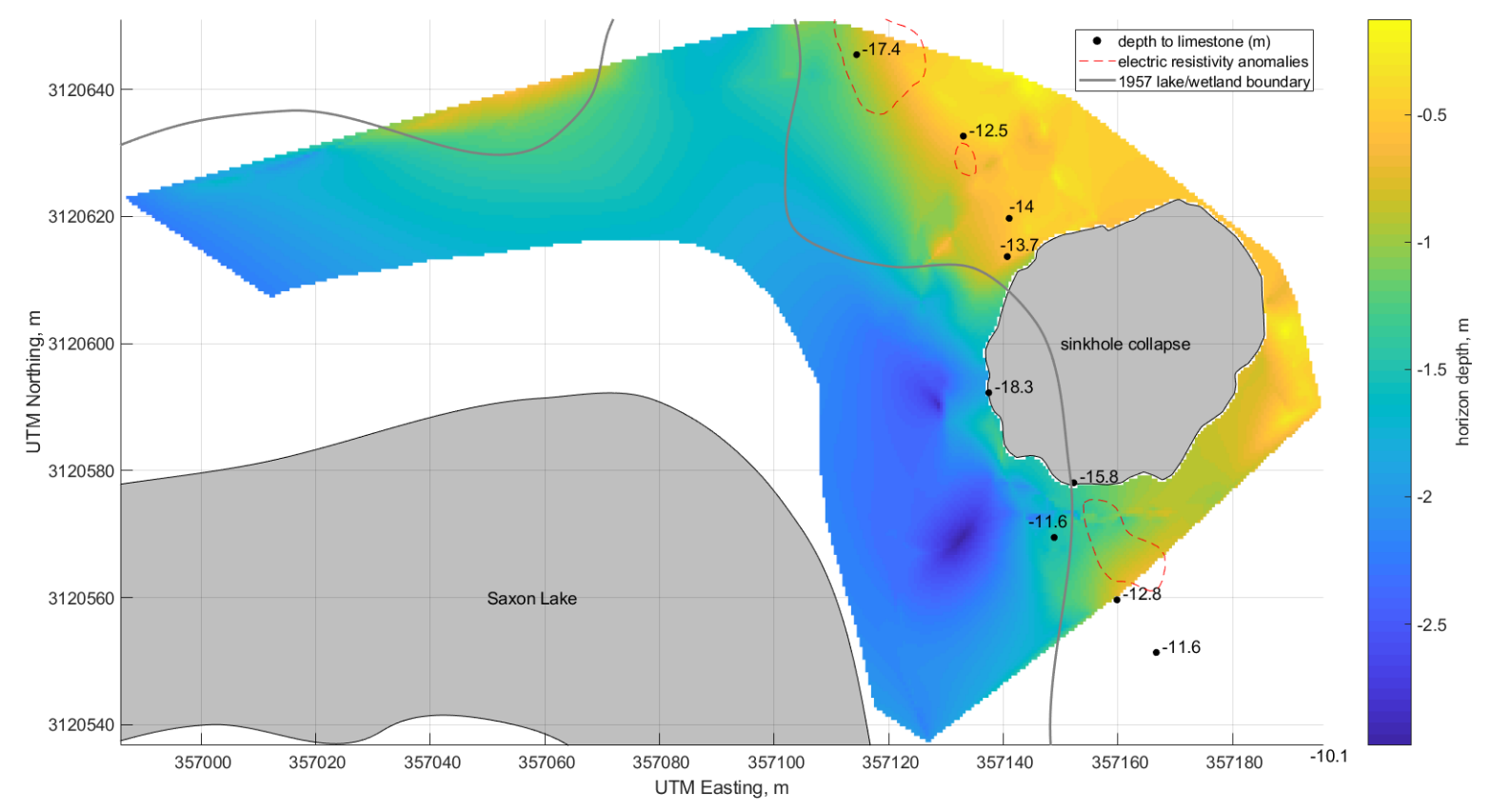

Figure 6. Interpolated surface of a semicontinuous horizon observed in numerous GPR profiles (Figure 5). The horizon resides within a sand to silt layer and corresponds to changes in physical properties, but not necessarily a lithological contact. It is shallowest $(<0.5 \mathrm{~m})$ to the east and northwest of the sinkhole and generally dips to the southwest. On the western edge of the sinkhole, the horizon appears shallow $(1.25-1.75 \mathrm{~m})$ and quickly becomes deeper $(2.5+\mathrm{m})$ to the southwest. Interruptions in the horizon (dotted red lines) may be due to local zones of subsidence. The areas in which the horizon is the deepest were once a part of the historic extent of Saxon Lake as seen in early aerial imagery (gray line). The top of limestone (points) is highly variable but is generally deepest around the sinkhole.

2018) there are large expected changes due to house and tree removals and a constructed stabilization rim. A negative change is also detected just southwest of the perimeter. This area experienced a large negative change (perimeter growth) in the first half of August, corresponding as well to when seismometers recorded activity in the sinkhole. This suggests continued failure of overburden (albeit potentially heavy machinery-induced) almost a month after the initial collapse. Regardless of the cause, failure is occurring in line with the long axis of the collapse.

When compared to historic lake edge boundaries (aerial imagery from 1957 and earlier), the horizon is about 1 meter or less deep outside historical lake extents and below 1 meter within extents. The lake's extent changed with time as the edge was filled using dredge muck from the Saxon Lake bottom to create more land for development (Henderson 1983). The horizon appears to represent a predevelopment surface.
The horizon is deepest ( 3 meters) to the southwest of the sinkhole. As indicated from soil borings, this is also where clay is the deepest and strata is more variable with alternating lithology starting approximately 14 meters below the surface. Interestingly, the deep portion also falls in line with the northeast-southwest long axis of the sinkhole. It is possible that the karst feature responsible for the collapse extends southwest. In that case, overburden, including the horizon, may be deepest in the southwest because this area subsided. This would agree with negative surface changes in the same area.

\section{Conclusions}

A combination of remote sensing, geophysics, and soil borings are used to characterize the temporospatial surface changes and subsurface structures at a cover-collapse sinkhole. The sinkhole is oval and cone-shaped with a northeast-southwest long axis and ridges on the northwest and west slopes. The initial collapse measured 1395 square meters and grew to a maximum of 1626 
square meters. The direction of the collapse's long axis, post-collapse activity, and the orientation and depth of a semicontinuous subsurface horizon suggests a linear or elongated karst feature responsible for the collapse. The historic lake edges also reveal the collapse - and characteristics just mentioned - spatially correspond to the lobe-like reach of the lake edge as it was in 1957 and earlier. This suggests the extent of lake bottom sediments may have played a role in the location of the collapse.

\section{Acknowledgements}

Thank you to HALO Imaging, Inc for contributing to the presented dataset with their UAV-based-photogrammetry; USF DHHC's Benjamin Mittler and Denise Wright for providing ArcGIS support; and the reviewers for their critical feedback that significantly improved the quality of this paper.

\section{Author Contributions}

In order of author list: Christine Downs conceived the presented idea, processed a portion of the terrestrial laser scan (TLS) data, carried out a portion of the groundpenetrating radar (GPR) fieldwork, performed the M3C2 analysis, and integrated data for analysis and presentation. Tonian Robinson carried out a portion of the GPR field work and processed the GPR data. Garret Speed designed and carried out the UAV-based SfM photogrammetry fieldwork, and processed the photogrammetry data. Jorge González García and Noelia García Asenjo, and Travis Doering designed and carried out the TLS fieldwork. Jorge González García and Noelia García Asenjo processed the majority of the TLS data. Lori Collins served as project manager, carried out the global positioning system (GPS) fieldwork, and conducted portions of the GIS analysis. Shawn Landry and David Eilers designed and carried out some of the bathymetric fieldwork and processed the data. Sarah Kruse, Sajad Jazayeri, Sanaz Esmaeili, Henok Kiflu designed and carried out the majority of GPR fieldwork. Jochen Braunmiller designed and carried out the seismic fieldwork and processed seismic data.

\section{References}

Benito-Calvo A, Gutiérrez F, Martínez-Fernández A, Carbonel D, Karampaglidis T, Desir G, Sevil J, Guerrero J, Fabregat I, García-Arnay Á. 2018. 4D Monitoring of Active Sinkholes with a Terrestrial Laser Scanner (TLS): A Case Study in the Evaporite Karst of the Ebro Valley, NE Spain. Remote Sensing. 10 (4).
Collins LD, Kiflu HG, Robinson T, Doering T, Eilers D, Rodgers M, Kruse S, Landry S, Braunmiller J, Speed G. 2017. A Multi-Sensor Approach to Documenting a Large Collapse Sinkhole in WestCentral Florida. AGU Fall Meeting Abstracts.

Colomina I, Molina P. 2014. Unmanned aerial systems for photogrammetry and remote sensing: A review. ISPRS journal of photogrammetry and remote sensing. 92:79-97.

Geotechnical Environmental Consultants. 2017. Report of Geotechnical Engineering Evaluation Pasco County Sinkhole.

Gómez-Ortiz D, Martín-Crespo T. 2012. Assessing the risk of subsidence of a sinkhole collapse using ground penetrating radar and electrical resistivity tomography. Engineering Geology. 149:1-12.

Gutiérrez F, Galve JP, Lucha P, Castañeda C, Bonachea J, Guerrero J. 2011. Integrating geomorphological mapping, trenching, InSAR and GPR for the identification and characterization of sinkholes: A review and application in the mantled evaporite karst of the Ebro Valley (NE Spain). Geomorphology. 134 (1-2):144-156.

Henderson SE. 1983. Hydrology of Lake Padgett, Saxon Lake, and Adjacent Area, Pasco County, Florida. United States Geological Survey.

James MR, Robson S, Smith MW. 2017. 3-D uncertainty-based topographic change detection with structure-from-motion photogrammetry: precision maps for ground control and directly georeferenced surveys. Earth Surface Processes and Landforms. 42 (12):1769-1788.

Jones L. 2006. Monitoring landslides in hazardous terrain using terrestrial LiDAR: an example from Montserrat. Quarterly Journal of Engineering Geology and Hydrogeology. 39 (4):371-373.

Lague D, Brodu N, Leroux J. 2013. Accurate 3D comparison of complex topography with terrestrial laser scanner: application to the Rangitikei canyon $(\mathrm{N}-\mathrm{Z})$. ISPRS journal of photogrammetry and remote sensing. 82:10-26.

Perroy RL, Bookhagen B, Asner GP, Chadwick OA. 2010. Comparison of gully erosion estimates using airborne and ground-based LiDAR on Santa Cruz 
Island, California. Geomorphology. 118 (3-4): 288-300.

Petschko H, Goetz J, Böttner M, Firla M, Schmidt S. 2017. Erosion processes and mass movements in sinkholes assessed by terrestrial structure from motion photogrammetry. Advances In Landslide Science; 2017.

Professional Service Industries. 2018. Geotechnical Engineering Services Report for the Ocean Pines Drive Sinkhole Investigation Land O' Lakes, Pasco County, Florida.

Sinclair WC, Stewart JW, Knutilla RL, Gilboy AE, Miller RL. 1985. Types, features, and occurence of sinkholes in the karst of west-central Florida. U.S. Geological Survey.

Tihansky AB. 1999. Sinkholes, west-central Florida. Land subsidence in the United States: US Geological Survey circular. 1182:121-140.

Tilly N, Kelterbaum D. 2017. Investigating the Surface and Subsurface in Karstic Regions--Terrestrial Laser Scanning versus Low-Altitude Airborne Imaging and the Combination with Geophysical Prospecting. AIMS GEOSCIENCES. 3 (3): 352-374.

Viles H. 2016. Technology and geomorphology: Are improvements in data collection techniques transforming geomorphic science? Geomorphology. 270: 121-133. 